\title{
Lower vitamin $D$ levels are associated with depression in patients with gout
}

This article was published in the following Dove Medical Press journal:

Neuropsychiatric Disease and Treatment

\section{Qiang Zhou \\ Yi-chuan Shao \\ Zheng-qi Gan \\ Li-shu Fang}

Department of Endocrinology, First Affiliated Hospital of Jiaxing University, Jiaxing, Zhejiang Province, China
Correspondence: Qiang Zhou

Department of Endocrinology, First Affiliated Hospital of Jiaxing University, 1882 Zhonghuan South Road, Jiaxing, Zhejiang Province 314000 , China

Tel +86 I599035I 2000

Email zhouqiang8005@I63.com
Background: Depression is commonly observed among patients with gout. Low levels of vitamin D have been associated with depression in non-gout subjects. We examined the association of vitamin D levels with depression in patients with gout.

Methods: We conducted a cross-sectional study of 186 gout patients at the Endocrinology Department of First Affiliated Hospital of Jiaxing University. Levels of serum 25-hydroxyvitamin $\mathrm{D}(25(\mathrm{OH}) \mathrm{D})$ were determined using a competitive protein-binding assay. The 17 -item Hamilton Depression Scale was used for screening for depressive symptoms. Diagnosis of depression in gout patients was made in accordance with Diagnostic and Statistical Manual of Mental Disorders, fifth edition criteria for depression. Multivariate analysis was performed using logistic regression models.

Results: Thirty-two gout patients (17.2\%) were diagnosed as having depression. Patients with depression showed significantly lower $25(\mathrm{OH}) \mathrm{D}$ levels as compared to patients without depression ( $46.4 \pm 19.0$ vs $57.0 \pm 17.3 \mathrm{nmol} / \mathrm{L}, P<0.001)$. Significant differences in $25(\mathrm{OH}) \mathrm{D}$ quartiles of gout patients were observed between the patients with depression and the patients without depression $(P=0.003)$. In multivariate analyses, serum $25(\mathrm{OH}) \mathrm{D}$ levels $(\leq 40.0 \mathrm{nmol} / \mathrm{L})$ were independently associated with depression in patients with gout (OR 3.833, 95\% CI 1.406-10.453, $P=0.009$ ).

Conclusion: Our study demonstrates an important association between serum vitamin D levels and depression in patients with gout.

Keywords: depression, vitamin, gout

\section{Introduction}

Gout is an inflammatory arthritis related to hyperuricemia that is triggered by the crystallization of uric acid within the joints. Gout is a common rheumatic disease worldwide, with an overall prevalence of $\sim 1.14 \%$ among Chinese adult population. ${ }^{1}$ Depression is frequently observed among patients with gout, with its prevalence ranging from $13 \%$ to $20 \% .^{2-5}$ The presence of depression has been associated with poorer medication adherence, reduced quality of life, and poorer management outcomes. ${ }^{6,7}$ Therefore, it is important to identify risk factors for the presence of depression in patients with gout.

Receptors of vitamin D have been detected in areas of the human brain involved in depression. ${ }^{8}$ An association between lower vitamin D levels and depression has been found in both healthy and clinical populations. ${ }^{9-12}$ Moreover, numerous randomized controlled trials have shown a positive effect of vitamin D supplementation on depression. ${ }^{13,14}$

A previous study has shown low levels of serum vitamin D among patients with gout and a significant association between low vitamin D levels and gout activity. ${ }^{15}$ To date, however, no study has investigated the possible association between vitamin $\mathrm{D}$ levels 
and depression in patients with gout. Given the involvement of vitamin $\mathrm{D}$ in depression in non-gout patients and the well-documented high prevalence of low vitamin D levels in gout patients, we conducted a cross-sectional study of 186 gout patients to determine the possible association of serum vitamin $\mathrm{D}$ levels with depression in gout patients.

\section{Methods}

\section{Participants}

Patients with gout were consecutively recruited from the Endocrinology Department of the First Affiliated Hospital of Jiaxing University between July 10, 2013 and May 18, 2017. Gout patients aged $\geq 18$ years and fulfilled the 1977 American College of Rheumatology preliminary criteria for the diagnostic of gout were included in this study. ${ }^{16}$ The exclusion criteria were: 1) patients with communication or cognitive disorders; 2) patients with pre-gout depression (clinical diagnosis or previous treatment) or other psychiatric disorders; 3) patients taking vitamin D replacement therapy. Meanwhile, 200 healthy volunteers without gout, vitamin $\mathrm{D}$ replacement therapy, or a history of psychiatric disorders including clinical diagnosis and previous treatment were recruited from a health survey. Written informed consents were obtained from all subjects or their relatives if the patients were illiterate. The study was approved by the Ethics Committee of the First Affiliated Hospital of Jiaxing University and was conducted in accordance with the principles of the Declaration of Helsinki.

\section{Clinical variables}

Demographic and clinical variables were obtained from participant report and electronic medical records. Demographic included age, sex, body mass index (BMI), and frequency of alcohol consumption. BMI was calculated as weight $(\mathrm{kg}) /$ squared height $\left(\mathrm{m}^{2}\right)$. Comorbidities included hypertension, hyperlipidemia, diabetes mellitus, stroke, coronary artery disease, and kidney failure. Gout-specific characteristics included: whether gout had ever been experienced in multiple joint at the same time, frequency of gout attacks in last 12 months, gout duration, and current medication use. A fasting morning venous blood sample was obtained from each participant. Levels of serum 25-hydroxyvitamin D $(25(\mathrm{OH}) \mathrm{D})$ were determined using a competitive proteinbinding assay (Hoffman-La Roche Ltd., Basel, Switzerland). The inter-assay variation coefficient for $25(\mathrm{OH}) \mathrm{D}$ measurement was $8.5 \%$. Serum $25(\mathrm{OH}) \mathrm{D}$ levels in gout patients were divided into four quartiles ( $\leq 41.0,41.1-55.0,55.1-66.0$, and $\geq 66.1 \mathrm{nmol} / \mathrm{L})$, as the raw data of $25(\mathrm{OH}) \mathrm{D}$ were skewed.

\section{Assessment of depression}

All gout patients were screened for depressive symptoms using 17-item Hamilton Depression Scale (HAMD-17). Patients with a HAMD-17 score of $\geq 7$ were given the Chinese version of the Structured Clinical Interview of the Diagnostic and Statistical Manual of Mental Disorders, fifth edition, for diagnosis of depression. These evaluations were administered by the same experienced psychologist who was blind to the laboratory results of gout patients, including serum levels of vitamin D.

\section{Statistical analyses}

Data were presented as number (percentage) for categorical variables, mean \pm SD for normally distributed variables, and medians (25th, 75th percentiles) for non-normally distributed variables. Comparisons between the groups were conducted using the chi-squared test, Fisher's exact test, Student's $t$-test, and Mann-Whitney $U$ test, as appropriate. Binary logistic regression including age, sex, and the factors with $P<0.05$ in the univariate analysis was performed to examine significant risk factors for depression in patients with gout. The abnormally distributed parameters were logtransformed for satisfying the log-linearity assumption. The results were presented as ORs with corresponding 95\% CIs. All statistical analyses were performed by using SPSS 22.0 (IBM Corporation, Armonk, NY, USA). Significance level was defined as $P$-value $<0.05$.

\section{Results}

\section{Baseline characteristics of the study samples}

Of 205 patients with gout, 19 were excluded from this analysis: 3 with a history of depression, 2 with a history of dementia, 4 taking vitamin $\mathrm{D}$ replacement therapy, and 10 who refused to participate in this study. There were no significant differences in age and sex between our study cohort $(\mathrm{n}=186)$ and those excluded. Of 186 participants, 151 were male (81.2\%) and their mean (SD) age was $61.9(10.9)$ years. The patients in this study did not differ from the controls in terms of age and sex.

\section{Univariate associations}

Of the 186 patients who formed the study sample, 32 (17.2\%, 26 men and 6 women) were diagnosed with depression. Eighteen depressed patients $(56 \%)$ agreed to have an antidepressant medication with selective serotonin reuptake inhibitors. Serum levels of $25(\mathrm{OH}) \mathrm{D}$ were markedly lower in patients with depression than in healthy controls (55.2 \pm 18.0 
vs $65.1 \pm 19.7 \mathrm{nmol} / \mathrm{L}, P<0.001)$. Patients with depression showed significantly lower $25(\mathrm{OH}) \mathrm{D}$ levels as compared to patients without depression ( $46.4 \pm 19.0$ vs $57.0 \pm 17.3 \mathrm{nmol} / \mathrm{L}$, $P<0.001)$. No correlation was detected between $25(\mathrm{OH}) \mathrm{D}$ levels and age, gender, calcium, phosphorus, albumin as well as with hemoglobin (all $P>0.05$ ). In addition, patients with depression had more gout attacks in multiple joint $(P<0.001)$ and higher frequency of gout attacks $(P<0.001)$. Significant differences in $25(\mathrm{OH}) \mathrm{D}$ quartiles of gout patients were observed between the patients with depression and the patients without depression $(P=0.003)$ (Table 1).

\section{Multivariate regressions}

With all gout patients taken as a whole, depression occurrence taken as a dependent variable, and quartile 2 and quartile 3 taken as the references used for serum 25(OH)D levels in the logistic analysis, 25(OH)D levels $(\leq 40.0 \mathrm{nmol} / \mathrm{L})$ were independently associated with depression in patients with gout (OR 3.833, 95\% CI 1.406-10.453, $P=0.009$ ). In addition, frequent gout attacks and attacks in multiple joints were significantly associated with depression in gout patients (OR 6.136, 95\% CI 1.737-21.674, $P=0.005$; OR 4.454, 95\% CI $1.468-13.512, P=0.008$, respectively) (Table 2).

Table I Patient characteristics stratified by depression

\begin{tabular}{|c|c|c|c|c|}
\hline Characteristics & $\begin{array}{l}\text { Patients with } \\
\text { depression }(n=32)\end{array}$ & $\begin{array}{l}\text { Patients without } \\
\text { depression }(n=154)\end{array}$ & $\begin{array}{l}\text { Healthy } \\
\text { volunteers }(n=200)\end{array}$ & $P$-value ${ }^{a}$ \\
\hline Age, mean $\pm S D$, years & $61.5 \pm 10.1$ & $62.0 \pm 11.1$ & $62.3 \pm 8.2$ & 0.820 \\
\hline Male, n (\%) & $26(8 \mathrm{I} .3)$ & $125(8 \mid .2)$ & $116(58.0)$ & 0.991 \\
\hline BMI, $\mathrm{kg} / \mathrm{m}^{2}$ & & & & 0.319 \\
\hline$<25.0$ & $14(43.8)$ & $43(27.9)$ & $59(29.5)$ & \\
\hline $25.0-29.9$ & $9(28.1)$ & $58(37.7)$ & $76(38.0)$ & \\
\hline $30.0-34.9$ & $5(15.6)$ & $36(23.4)$ & $45(22.5)$ & \\
\hline$\geq 35.0$ & $4(12.5)$ & $17(\mid 1.0)$ & $20(10.0)$ & \\
\hline Alcohol consumption, n (\%) & & & & 0.557 \\
\hline Daily & $8(25.0)$ & $43(28.3)$ & & \\
\hline 3-4 times per week & $9(28.1)$ & $30(19.7)$ & & \\
\hline $\mathrm{I}-2$ times per week & $7(21.9)$ & $32(21.1)$ & & \\
\hline Occasionally & $3(9.4)$ & $30(19.7)$ & & \\
\hline Never & $5(15.6)$ & $17(11.2)$ & & \\
\hline \multicolumn{5}{|l|}{ Comorbidity, n (\%) } \\
\hline Hypertension & $21(65.6)$ & $88(57.1)$ & & 0.375 \\
\hline Diabetes mellitus & $7(21.9)$ & $21(13.5)$ & & 0.223 \\
\hline Coronary heart disease & $4(12.5)$ & $14(8.8)$ & & 0.511 \\
\hline Hyperlipidemia & $15(46.9)$ & $60(39.0)$ & & 0.406 \\
\hline Stroke & $2(6.3)$ & $7(4.5)$ & & 0.654 \\
\hline Kidney failure & $3(9.4)$ & $7(4.5)$ & & 0.380 \\
\hline \multicolumn{5}{|l|}{ Gout characteristics } \\
\hline Gout duration, median (IQR), years & $6(4-11)$ & $6(3-8)$ & & 0.178 \\
\hline Frequency of gout attacks & & & & $<0.001$ \\
\hline 0 & $6(18.8)$ & $53(34.4)$ & & 0.083 \\
\hline $\mathrm{I}-2$ & $9(28.1)$ & $82(53.2)$ & & 0.010 \\
\hline$\geq 3$ & $17(53.1)$ & $19(12.3)$ & & $<0.001$ \\
\hline Gout attacks in multiple joint & $25(78.1)$ & $46(29.9)$ & & $<0.001$ \\
\hline \multicolumn{5}{|l|}{ Current medication use, $\mathrm{n}(\%)$} \\
\hline Allopurinol & $17(53.1)$ & $92(57.9)$ & & 0.489 \\
\hline NSAID & $12(37.5)$ & $44(28.6)$ & & 0.316 \\
\hline Corticosteroids & $3(9.4)$ & $11(7.1)$ & & 0.712 \\
\hline $25(\mathrm{OH}) \mathrm{D}, \mathrm{n}(\%)$ & & & & 0.003 \\
\hline Quartile I & $14(43.8)$ & $28(18.2)$ & & 0.002 \\
\hline Quartile 2 & $9(28.1)$ & $31(20.1)$ & & 0.317 \\
\hline Quartile 3 & $4(12.5)$ & $39(25.3)$ & & 0.117 \\
\hline Quartile 4 & $5(\mid 5.6)$ & $56(36.4)$ & & 0.023 \\
\hline $25(\mathrm{OH}) \mathrm{D}$, mean $\pm \mathrm{SD}, \mathrm{nmol} / \mathrm{L}$ & $46.4 \pm 19.0$ & $57.0 \pm 17.3$ & $65.1 \pm 19.7$ & 0.002 \\
\hline
\end{tabular}

Notes: Data are expressed as number (percentage) or mean \pm SD or medians (IQR). ${ }^{a}$ Compared between the patients with depression and the patients without depression. Abbreviations: BMI, body mass index; 25(OH)D, 25-hydroxyvitamin D. 
Table 2 Characteristics associated with depression in gout patients $^{\mathrm{a}}$

\begin{tabular}{l|l|l}
\hline Variables & OR (95\% Cl) & $P$-value \\
\hline $25(\mathrm{OH}) \mathrm{D}^{\mathrm{b}}$ & $3.833(1.406-10.453)$ & 0.009 \\
Gout attacks in multiple joint & $4.454(1.468-13.512)$ & 0.008 \\
Frequent gout attacks $(\geq 3)$ & $6.136(1.737-21.674)$ & 0.005 \\
Age & $0.986(0.945-1.029)$ & 0.520 \\
Sex & $1.011(0.322-3.176)$ & 0.985 \\
\hline
\end{tabular}

Note: ancludes age, sex, and the variables which were significant $(P<0.05)$ in the multivariable model; ' quartile I.

Abbreviation: 25(OH)D, 25-hydroxyvitamin D.

\section{Discussion}

To the best of our knowledge, this is the first study exploring the possible association between serum vitamin $\mathrm{D}$ levels and depression among gout patients. Our results suggest that serum level of vitamin D was significantly associated with depression in patients with gout, which is similar to the findings of previous studies in elderly adults and patients with chronic spinal cord injury. ${ }^{10,11}$ Our findings might have important implications in providing novel therapeutic target for depression in patients with gout.

In the present study, $17.2 \%$ of gout patients were diagnosed as having depression, which is consistent with the results of earlier studies. ${ }^{2}$ Currently, despite the available literature, it remains difficult to determine the actual prevalence of depression in gout patients, possibly due to the differences in study designs, the source of patient recruitment, methods used to diagnose depression, and race/ethnicity. In addition, our results demonstrated that frequent gout attacks and attacks in multiple joints were risk factors for depression in gout patients, which agrees with the findings of previous studies. ${ }^{5}$

Interestingly, we found that serum vitamin D levels were independently associated with depression in gout patients. As mentioned earlier, numerous studies have demonstrated an important association of low vitamin D levels and depression in non-gout subjects. The exact mechanisms by which vitamin D could affect depression are unclear. Vitamin D receptors and vitamin D activating enzyme 1a-hydroxylase are broadly present in specific regions of the human brain, some of which have been involved in the pathophysiology of depression, including the cingulate cortex, hippocampus, hypothalamus, and substantia nigra. ${ }^{8}$ Vitamin D response elements have been detected in the promoter regions of serotonin genes. ${ }^{17}$ Another possible explanation is the effect of vitamin D on inflammatory response. Vitamin D plays a vital role in modulating the secretion of inflammatory cytokines such as IL- 6 and IL-1 $\beta{ }^{18,19}$ Gout is considered to be a chronic inflammatory disease, characterized by elevated inflammatory factors such as IL- 6 and IL-1 $\beta .{ }^{20}$ It has been hypothesized that depression and gout may share common pathophysiological mechanisms including inflammatory response and immune activation. ${ }^{20-22}$ Vitamin D may modulate the association between depression and inflammatory response through its effect on the immune system. Hence, these abovementioned results suggest that vitamin D might play a key role in depression in gout patients.

\section{Limitations}

There are several limitations in this study. First, the seasonal variation of vitamin D levels makes it preferable to perform the measurements on the same day. Second, subjects in our sample were recruited from only one clinic, which limited the generalization of the findings. Third, due to lack of data of uric acid levels, we could not analyze the possible association between uric acid levels and depression in gout patients. Finally, the small sample size may reduce the statistical power of the present study.

\section{Conclusion}

In summary, despite of these limitations mentioned above, our study demonstrates an important association between vitamin D levels and depression in patients with gout. Further randomized controlled trials are critical in examining whether the supplement of vitamin D holds promise for the treatment of depression in gout patients.

\section{Acknowledgment}

The authors express their gratitude to all subjects who participated in the current study.

\section{Disclosure}

The authors report no conflicts of interest in this work.

\section{References}

1. Liu R, Han C, Wu D, et al. Prevalence of hyperuricemia and gout in mainland China from 2000 to 2014: a systematic review and metaanalysis. Biomed Res Int. 2015;2015:1-12.

2. Fu T, Cao H, Yin R, et al. Depression and anxiety correlate with diseaserelated characteristics and quality of life in Chinese patients with gout: a case-control study. Psychol Health Med. 2018;23(4):400-410.

3. Lin S, Zhang H, Ma A. Association of gout and depression: a systematic review and meta-analysis. Int J Geriatr Psychiatry. 2018;33(3): 441-448.

4. Mak A, Tang CS, Chan MF, Cheak AA, Ho RC. Damage accrual, cumulative glucocorticoid dose and depression predict anxiety in patients with systemic lupus erythematosus. Clin Rheumatol. 2011;30(6):795-803.

5. Prior JA, Mallen CD, Chandratre P, Muller S, Richardson J, Roddy E. Gout characteristics associate with depression, but not anxiety, in primary care: baseline findings from a prospective cohort study. Joint Bone Spine. 2016;83(5):553-558. 
6. May HT, Sheng X, Catinella AP, Horne BD, Carlquist JF, Joy E. Antilipidemic adherence post-coronary artery disease diagnosis among those with and without an ICD-9 diagnosis of depression. J Psychosom Res. 2010;69(2):169-174.

7. Rieckmann N, Kronish IM, Haas D, et al. Persistent depressive symptoms lower aspirin adherence after acute coronary syndromes. Am Heart J. 2006;152(5):922-927.

8. Eyles DW, Smith S, Kinobe R, Hewison M, McGrath JJ. Distribution of the vitamin D receptor and 1 alpha-hydroxylase in human brain. J Chem Neuroanat. 2005;29(1):21-30.

9. Amini S, Jafarirad S, Amani R. Postpartum depression and vitamin D: a systematic review. Crit Rev Food Sci Nutr. Epub 2018 Feb 02.

10. Barbonetti A, Cavallo F, D'Andrea S, et al. Lower Vvitamin D levels are associated with depression in people with chronic spinal cord injury. Arch Phys Med Rehabil. 2017;98(5):940-946.

11. Hoogendijk WJ, Lips P, Dik MG, Deeg DJ, Beekman AT, Penninx BW. Depression is associated with decreased 25-hydroxyvitamin D and increased parathyroid hormone levels in older adults. Arch Gen Psychiatry. 2008;65(5):508-512.

12. Sherchand O, Sapkota N, Chaudhari RK, et al. Association between vitamin D deficiency and depression in Nepalese population. Psychiatry Res. 2018;267:266-271.

13. Shaffer JA, Edmondson D, Wasson LT, et al. Vitamin D supplementation for depressive symptoms: a systematic review and metaanalysis of randomized controlled trials. Psychosom Med. 2014;76(3): 190-196.
14. Vellekkatt F, Menon V. Efficacy of vitamin D supplementation in major depression: a meta-analysis of randomized controlled trials. J Postgrad Med. Epub 2018 Jun 21.

15. Takahashi S, Yamamoto T, Moriwaki Y, Tsutsumi Z, Yamakita J, Higashino K. Decreased serum concentrations of 1,25(OH)2-vitamin D3 in patients with gout. Adv Exp Med Biol. 1998;431:57-60.

16. Wallace SL, Robinson H, Masi AT, Decker JL, McCarty DJ, Yü TF. Preliminary criteria for the classification of the acute arthritis of primary gout. Arthritis Rheum. 1977;20(3):895-900

17. Wang TT, Tavera-Mendoza LE, Laperriere D, et al. Large-scale in silico and microarray-based identification of direct 1,25-dihydroxyvitamin D3 target genes. Mol Endocrinol. 2005;19(11):2685-2695.

18. Roy P, Nadeau M, Valle M, et al. Vitamin D reduces LPS-induced cytokine release in omental adipose tissue of women but not men Steroids. 2015;104:65-71.

19. Sommer A, Fabri M. Vitamin D regulates cytokine patterns secreted by dendritic cells to promote differentiation of IL-22-producing T cells. PLoS One. 2015;10(6): 0130395.

20. Cavalcanti NG, Marques CD, Lins E Lins TU, et al. Cytokine profile in gout: inflammation driven by IL-6 and IL-18? Immunol Invest. 2016;45(5):383-395.

21. Alexopoulos GS, Morimoto SS. The inflammation hypothesis in geriatric depression. Int J Geriatr Psychiatry. 2011;26(11):1109-1118.

22. Song C, Wang H. Cytokines mediated inflammation and decreased neurogenesis in animal models of depression. Prog Neuropsychopharmacol Biol Psychiatry. 2011;35(3):760-768.
Neuropsychiatric Disease and Treatment

\section{Publish your work in this journal}

Neuropsychiatric Disease and Treatment is an international, peerreviewed journal of clinical therapeutics and pharmacology focusing on concise rapid reporting of clinical or pre-clinical studies on a range of neuropsychiatric and neurological disorders. This journal is indexed on PubMed Central, the 'PsycINFO' database and CAS,

\section{Dovepress}

and is the official journal of The International Neuropsychiatric Association (INA). The manuscript management system is completely online and includes a very quick and fair peer-review system, which is all easy to use. Visit http://www.dovepress.com/testimonials.php to read real quotes from published authors. 